\title{
Analisis Faktor-Faktor yang Mempengaruhi Kepatuhan Wajib Pajak Orang Pribadi dalam Memenuhi Kewajiban Membayar Pajak Kendaraan Bermotor (PKB)
}

\author{
Eldasari. $Z^{\mathrm{i}}$, Irwan ${ }^{\mathrm{ii}}$, Adnan Sauddin ${ }^{\text {iii }}$
}

\footnotetext{
${ }^{i}$ Mahasiswa Universitas Islam Negeri Alauddin Makassar,,60600114036@uin-alauddin.ac.id

${ }^{i i}$ Universitas Islam Negeri Alauddin Makassar, irwan.msi@uin-alauddin.ac.id

iii Universitas Islam Negeri Alauddin Makassar, adnan.sauddin@uin-alauddin.ac.id
}

ABSTRACT, In this article, discussed about the factors that influence individual taxpayer compliance to pay vehicles tax such as motorcycle, car, and truck. The growth in the number of vehicles increasing rapidly, related to what is a problem in paying vehicles tax. There are several reasons, including taxpayer compliance to pay vehicles tax. In this article, there are 18 measurement indicators that influencing of this object. These measurement indicators then grouped into several factors using Eksploratory Factor Analysis (EFA). The results showed that there were five factors that influenced taxpayer compliance to pay vehicles tax. The first factor is service quality, the second factor is spatial planning and tax administration, the third factor is tax socialization, the fourth factor is knowledge and understanding of taxation, and the fifth factor is education.

Keywords: Exploratory Factor Analysis (EFA), eigen value, Principal Component Analysis (PCA), Varimax Rotation, taxpayer.

\section{PENDAHULUAN}

Sumber pendapatan negara Indonesia yang cukup besar dan penting bagi pembangunan nasional adalah pajak. Pajak cukup potensial sebagai penerimaan negara maupun daerah. Salah satu jenis pendapatan pajak daerah adalah Pajak Kendaraan Bermotor (PKB). Pajak Kendaraan Bermotor (PKB) adalah pajak atas kepemilikan dan atau penguasaan kendaraan bermotor. Pajak Kendaraan Bermotor (PKB) merupakan salah satu sumber pajak daerah yang memiliki potensial yang cukup besar.

Perkembangan kendaraan bermotor di Takalar sangat pesat. Setiap harinya ada saja kendaraan baru yang terdaftar di Samsat Takalar. Melihat hal ini, seharusnya pemerintah dapat memaksimalkan pemasukan dana dari pajak PKB. Akan tetapi, dilihat dari realisasinya pemerintah belum bisa memaksimalkan pendapatan dari sektor ini karena masih banyak wajib pajak yang tidak patuh dalam membayar pajak PKB.

Dari banyaknya faktor yang mempengaruhi kepatuhan wajib pajak, maka faktor tersebut akan direduksi menjadi beberapa kelompok yang lebih sedikit sehingga memudahkan untuk mengantisipasi terjadinya penunggakan pajak yang lebih besar. Ada beberapa metode yang bisa digunakan untuk mereduksi variabel yaitu Analisis Faktor Eksploratori atau Eksploratory Factor Analysis (EFA) dan Analisis Faktor Konfirmatori atau Confirmatory Factor Analysis (CFA). Namun, peneliti hanya menggunakan metode Analisis Faktor Eksploratori karena tidak dilakukan hipotesis yang bersifat teoritis dalam menggunakan analisis faktor, sehingga kesimpulan pengelompokan pada faktor-faktor akan dibuat berdasarkan hasil yang diperoleh dalam analisis. Sedangkan Analisis Faktor Konfirmatori mempunyai informasi yang bersfat teoritis tentang struktur yang mendasari data dan diharapkan akan dihasilkan faktor yang sesuai dengan hipotesis tersebut sehingga sering dilakukan perulangan analisis, jika hasil pengujian model ternyata tidak sesuai dengan apa yang dihipotesiskan.

Analisis faktor dipilih karena merupakan metode yang dapat digunakan untuk mereduksi data yaitu suatu proses untuk meringkas sejumlah variabel independen yang saling berkorelasi untuk dikelompokan menjadi sebuah variabel baru yang diberi nama faktor dan variabel yang berada dalam satu kelompok merupakan variabel yang memiliki hubungan yang tinggi antara satu dengan yang lainnya.

\section{TINJAUAN PUSTAKA}

Analisis faktor adalah suatu teknik interdependensi (kebergantungan antara) yang tujuan utamanya adalah untuk mendefenisikan struktur diantara variabel yang diteliti. Variabelvariabel tersebut apakah mereka berdiri sendirisendiri atau mereka merupakan kumpulan variabel yang secara berkelompok menjelaskan tentang suatu keadaan. Dalam hal tersebut, variabel yang berada dalam satu kelompok merupakan variabel yang memiliki hubungan 
yang tinggi antara satu dengan yang lainnya. Dengan kata lain, variabel-variabel yang tingkat korelasinya antara satu dengan yang lainnya tinggi dinyatakan sebagai satu kelompok variabel (faktor)[1].

Vektor acak teramati $\mathrm{X}$, dengan $p$ komponen mempunyai vektor rata-rata $(\boldsymbol{\mu})$ dan matriks kovariansi $(\boldsymbol{\Sigma})$. Model faktor X adalah terjadinya independen linear sekumpulan kecil variabel acak tak teramati, $F_{1}, F_{2}, \ldots, F_{m}$ disebut common factor, dan $p$ sumber variasi tambahan $\varepsilon_{1}, \varepsilon_{2}, \ldots, \varepsilon_{p}$ disebut error atau kadang disebut juga faktor khusus. Model analisis faktor adalah sebagai berikut[2]:

$\mathrm{X}_{1}-\mu_{1}=l_{11} F_{1}+l_{12} F_{2}+\ldots l_{l m} F m+\varepsilon_{1}$

$\mathrm{X}_{2}-\mu_{2}=l_{21} F_{1}+l_{22} F_{2}+\ldots l_{2 m} F m+\varepsilon_{2}$

$\mathrm{X}_{p}-\mu_{p}=l_{p 1} F_{1}+l_{p 2} F_{2}+\ldots l_{p m} F m+\varepsilon_{p}$

Atau dalam notasi matriks yaitu:

$\boldsymbol{X}_{(p x l)}-\boldsymbol{\mu}_{(p x l)}=\boldsymbol{L}_{(p x m)} \boldsymbol{F}_{(m x l)}+\boldsymbol{\varepsilon}_{(p x l)}$

Keterangan :

$$
\begin{aligned}
\mathrm{X}_{p}= & \text { Variabel asal } \\
\mu_{p}= & \text { Rataan ke- } p \\
\mathrm{l}_{p m}= & \text { Faktor pembobot ( faktor loading dari } \\
& \text { variabel ke- } p \text { pada faktor ke- } m \text { ) } \\
F_{m}= & \text { Faktor bersama (common factor) ke- } m \\
\varepsilon_{p}= & \text { Galat (errors) atau faktor khusus } \\
m= & \text { Banyaknya faktor bersama (common } \\
& \text { factor) }
\end{aligned}
$$

Koefisisen $\mathrm{l}_{p m}$ disebut loading dari variable ke$p$ pada faktor ke- $m$, dengan demikian matriks $\boldsymbol{L}$ merupakan matriks faktor loading. Perhatikan bahwa faktor khusus ke- $p, \varepsilon_{p}$, hanya berkaitan dengan respon ke- $p$ dari $\mathrm{X}_{p}$.

Jumlah besaran yang tak teramati yang cukup banyak, verifikasi secara langsung model faktor dari pengamatan $\mathrm{X}_{1}, \mathrm{X}_{2}, \ldots, \mathrm{X}_{p}$ kurang membantu. Namun demikian dengan beberapa tambahan asumsi seputar vektor acak $\boldsymbol{F}$ dan $\boldsymbol{\varepsilon}$, model (0.2) memberikan implikasi hubungan kovariansi tertentu, yang dapat diperiksa.

Asumsikan bahwa:

$$
\begin{aligned}
& E \mathbf{F}=\underset{m \times 1}{0}, \operatorname{cov} \mathbf{F}=E\left[\mathbf{F F}^{\prime}\right]=\underset{m \times m}{\mathbf{I}} \quad E \varepsilon=\underset{p \times 1}{0} \\
& \operatorname{cov} \boldsymbol{\varepsilon}=E\left[\boldsymbol{\varepsilon} \varepsilon^{\prime}\right]=\underset{p \times p}{\mathbf{M}}=\left[\begin{array}{cccc}
M_{1} & 0 & \cdots & 0 \\
0 & M_{2} & \cdots & 0 \\
\vdots & \vdots & \ddots & \vdots \\
0 & 0 & \cdots & M_{p}
\end{array}\right]
\end{aligned}
$$

Dan $\boldsymbol{F}$ dan $\boldsymbol{\varepsilon}$ adalah independen, sehingga:

$$
\operatorname{cov} \varepsilon, \mathbf{F}=E \varepsilon \mathbf{F}^{\prime}=\underset{p \times m}{0}
$$

Asumsi-asumsi diatas dan persamaan disebut sebagai model faktor orthogonal.

Struktur kovariansi untuk model faktor orthogonal adalah sebagai berikut:

a. $\operatorname{cov} \mathbf{X}=\mathbf{L} \mathbf{L}^{\prime}+\mathbf{M}$

atau

$$
\begin{aligned}
\operatorname{var} X_{i} & =\ell_{i 1}^{2}+\cdots+\ell_{i m}^{2}+M_{i} \\
\operatorname{cov} X_{i}, X_{j} & =\ell_{i 1} \ell_{j 1}+\cdots+\ell_{i m} \ell_{j m}
\end{aligned}
$$

b. $\operatorname{cov} \mathbf{X}, \mathbf{F}=\mathbf{L}$

atau

$$
\operatorname{cov} X_{i}, F_{j}=\ell_{i j}
$$

Bagian dari variansi variable ke- $i$ yang berkonstribusi dengan $m$ common factor disebut communality. Bagian dari var $\mathrm{X}_{i}=\sigma_{i i}$ tersebut yang menyatakan faktor tertentu sering disebut uniqueness atau variansi tertentu.

\section{Uji Kesesuaian Model}

Pengujian terhadap matriks korelasi antar variabel dilakukan dengan tiga uji statistik yaitu Uji Kaiser Meyer Oikin (KMO), Uji Bartlett, dan Uji Measures of Sampling Adequacy (MSA).

\section{Uji Kaiser Mayer Oikin (KMO)}

Uji Kaiser Meyer Oikin (KMO) bertujuan untuk mengetahui semua data yang terambil telah layak untuk analisis faktor. Adapun formula untuk menghitung KMO sebagai berikut:

$H_{0}$ : Jumlah data cukup untuk difaktorkan

$H_{1}$ : Jumlah data tidak cukup untuk difaktorkan

$$
\mathrm{KMO}=\frac{\sum_{i=1}^{p} \sum_{j=1}^{p} r_{i j}^{2}}{\sum_{i=1}^{p} \sum_{j=1}^{p} r_{i j}^{2}+\sum_{i=1}^{p} \sum_{j=1}^{p} a_{i j}^{2}}
$$

Keterangan :

$$
\begin{array}{lll}
\mathrm{i} & =1,2,3, \ldots, p & \text { dan } \\
\mathrm{j} & =1,2,3, \ldots, p, & \mathrm{j} \neq \mathrm{i}
\end{array}
$$




$$
\begin{aligned}
r_{i j}{ }^{2}= & \text { Koefisien korelasi sederhana antara } \\
& \text { variabel } \mathrm{i} \text { dan } \mathrm{j} \\
a_{i j}{ }^{2}= & \begin{array}{l}
\text { Koefisien korelasi parsial antara } \\
\text { variabel } \mathrm{i} \text { dan } \mathrm{j}
\end{array}
\end{aligned}
$$

\section{Uji Bartlett's}

Uji Bartlett's bertujuan untuk mengetahui apakah terdapat hubungan antar variabel. Jika variabel $X_{1}, X_{2}, \ldots, X_{p}$ independent (bersifat saling bebas), maka matriks korelasi antar variabel sama dengan matriks identitas. Sehingga untuk menguji kebebasan ini, uji Bartlett's menyatakan hipotesis sebagai berikut:

$H_{0}$ : Matriks korelasi merupakan matriks Identitas $(\mathrm{p}=\mathrm{I})$

$H_{1}$ : Matriks korelasi bukan merupakan matriks Identitas $(p \neq I)$

Uji statistik :

$$
\begin{aligned}
& \bar{r}_{k}=\frac{1}{p-1} \sum_{i=1}^{p} r_{i k}, \quad \mathrm{k}=1,2, \ldots, \mathrm{p} \\
& \bar{r}=\frac{2}{p(p-1)} \sum \sum_{i<k} r_{i k} \\
& \hat{\gamma}=\frac{(p-1)^{2}\left[1-(1-\bar{r})^{2}\right\rfloor}{p-(p-2)(1-\bar{r})^{2}}
\end{aligned}
$$

Dengan :

$\bar{r}_{k}=$ rata-rata elemen diagonal pada kolom atau baris ke $\mathrm{k}$ dari matriks $\mathrm{R}$ (matriks korelasi )

$\bar{r}=$ rata-rata keseluruhan dari elemen diagonal

\section{Uji Measure Sampling Adequacy (MSA)}

MSA sesungguhnya merupakan sebuah statistik yang berguna untuk mengukur seberapa tepat suatu variabel terprediksi oleh variabel lain dengan error yang relatif kecil. Formulasi perhitungannya adalah dengan membandingkan antara korelasi terobservasi dengan korelasi parsial.

Perhitungan secara matematis dirumuskan dengan:

$$
M S A_{i}=\frac{\sum \sum r_{i j}{ }^{2}}{\sum \sum r_{i j}{ }^{2}+\sum \sum a_{i j}{ }^{2}} \quad \text { untuk } \mathrm{i} \neq \mathrm{j}
$$

Dimana:

$\mathrm{i} \quad=1,2, \ldots \mathrm{q}$ banyaknya variabel

$r_{i j}{ }^{2}=$ koefisien korelasi antara variabel $\mathrm{i}$ dan $\mathrm{j}$

$a_{i j}{ }^{2}=$ koefisien parsial antara variabel $i$ dan $\mathrm{j}$

\section{Ekstraksi Faktor}

Ekstraksi faktor yang bertujuan untuk mengetahui jumlah faktor yang terbentuk dari data yang ada. Pada tahap ini, akan dilakukan proses inti dari analisis faktor, yaitu melakukan ekstraksi terhadap sekumpulan variabel yang ada $\mathrm{KMO}>0,5$ sehingga terbentuk satu atau lebih faktor. Metode ekstrasi yang digunakan adalah Analisis Komponen Utama atau Principal Components Analysis (PCA).

Analisis komponen utama bertujuan untuk menyederhanakan variabel yang diamati dengan cara menyusutkan dimensinya. Hal ini dilakukan dengan menghilangkan korelasi variabel melalui transformasi variabel asal ke variabel baru yang tidak berkorelasi. Variabel baru $(Y)$ disebut komponen utama yang merupakan hasil transformasi dari variable asal $X$ yang modelnya dalam bentuk catatan matriks adalah :

$$
Y=A X
$$

Dengan :

$\mathrm{A}=$ Matriks yang melakukan transformasi terhadap variable asal $x$ sehingga diperoleh vektor komponen $y$.

Penjabarannya adalah sebagai berikut[3]

$$
Y=\left[\begin{array}{c}
y_{1} \\
y_{2} \\
\vdots \\
y_{p}
\end{array}\right], A=\left[\begin{array}{cccc}
a_{11} & a_{12} & \cdots & a_{1 p} \\
a_{21} & a_{22} & \cdots & a_{2 p} \\
\vdots & \vdots & \ddots & \vdots \\
a_{1 p} & a_{2 p} & \cdots & a_{p p}
\end{array}\right], X=\left[\begin{array}{c}
x_{1} \\
x_{2} \\
\vdots \\
x_{p}
\end{array}\right]
$$

\section{Rotasi Faktor}

Rotasi faktor bertujuan agar dapat memperoleh struktur faktor yang lebih sederhana agar mudah diinterpretasikan. Pada rotasi faktor, matriks faktor ditransformasikan ke dalam matriks yang lebih sederhana, sehingga lebih mudah diinterpretasikan. Rotasi faktor yang digunakan adalah rotasi Orthogonal dengan metode varimax. Metode varimax adalah metode rotasi orthogonal untuk meminimalisasi jumlah indikator yang mempunyai faktor loading tinggi pada tiap faktor.

$$
\begin{aligned}
X_{1}-\mu_{1} & =\ell_{11} F_{1}+\ell_{12} F_{2}+\cdots+\ell_{1 m} F_{m}+\varepsilon_{1} \\
X_{p}-\mu_{p} & =\ell_{p 1} F_{1}+\ell_{p 2} F_{2}+\cdots+\ell_{p m} F_{m}+\varepsilon_{p}
\end{aligned}
$$

Dengan :

$$
\begin{aligned}
F_{j}= & \text { Common factor } \mathrm{ke}-\mathrm{j} \\
\ell_{i j}= & \text { loading factor } \mathrm{ke}-\mathrm{j} \text { dari variabel ke- } \mathrm{i} \\
\varepsilon_{1}= & \text { specific factor } \mathrm{ke}-\mathrm{i}, \mathrm{i}=1,2, \ldots, \mathrm{p} \text { dan } \mathrm{j}= \\
& 1,2, \ldots, \mathrm{m}
\end{aligned}
$$


Dalam notasi matriks persamaan dapat ditulis sebagai berikut:

$$
\boldsymbol{X}_{(p x 1)}=\boldsymbol{\mu}_{(p x 1)}+\boldsymbol{L}_{(p x m)} \boldsymbol{F}_{(m x 1)}+\boldsymbol{\varepsilon}_{(p x 1)}
$$

Dengan :

$$
\begin{aligned}
\mu_{i}= & \text { rata-rata variabel } i \\
\varepsilon_{i}= & \text { faktor spesifik } \mathrm{ke}-i \\
F_{i}= & \text { common faktor ke }-j \\
l_{i i}= & \text { loading dari variabel } \mathrm{ke}-i \text { pada faktor } \\
& \text { ke }-j
\end{aligned}
$$

\section{Pajak Kendaraan Bermotor (PKB)}

Pajak adalah kontribusi wajib kepada Daerah yang terutang oleh orang pribadi atau badan yang bersifat memaksa berdasarkan undang-undang, dengan tidak mendapatkan imbalan secara langsung dan digunakan untuk keperluan daerah bagi sebesar-besarnya kemakmuran rakyat. Pajak Kendaraan Bermotor (PKB) adalah pajak atas kepemilikan dan atau penguasaan kendaraan bermotor. Wajib pajak sering disingkat dengan WP. Wajib pajak adalah orang pribadi atau badan, meliputi pembayar pajak, pemotong pajak, dan pemungut pajak, yang mempunyai hak dan kewajiban perpajakan sesuai dengan ketentuan peraturan perundang-undangan perpajakan[4].

Kepatuhan wajib pajak merupakan dimana wajib pajak memenuhi kewajiban perpajakannya dan melaksanakan hak perpajakan dengan baik dan benar sesuai dengan peraturan dan undangundang pajak yang berlaku. Kepatuhan wajib pajak meliputi yaitu memenuhi kewajiban pajak sesuai dengan ketentuan yang berlaku, membayar pajaknya tepat pada waktunya, wajib pajak memenuhi persyaratan dalam membayar pajaknya, dan wajib pajak mengetahui jatuh tempo pembayaran[5].

\section{METODOLOGI}

Data yang digunakan dalam penelitian ini adalah data primer.

\section{Variabel Penelitian}

Variabel yang digunakan dalam penelitian ini yaitu: Tarif pajak yang sesuai $\left(\mathrm{X}_{1}\right)$, Pengetahuan terhadap denda pajak $2 \%$ per bulan $\left(\mathrm{X}_{3}\right)$, Penertiban pajak $\left(\mathrm{X}_{5}\right)$, Pajak sumber pemasukan dana terbesar $\left(\mathrm{X}_{6}\right)$, Pajak sumber pendapatan $\left(\mathrm{X}_{7}\right)$, Tingkat pendidikan $\left(\mathrm{X}_{8}\right)$, Sosialisasi pembayaran pajak $\left(\mathrm{X}_{9}\right)$, Sosialisasi pajak $\left(\mathrm{X}_{10}\right)$,
Kemampuan petugas samsat dalam membantu dan menjawab pertanyaan tentang pajak $\left(\mathrm{X}_{11}\right)$, Sikap tanggap petugas samsat dalam menyelesaikan masalah $\left(\mathrm{X}_{12}\right)$, Kemampuan petugas samsat menjelaskan tata cara pembayaran pajak dengan baik $\left(\mathrm{X}_{13}\right)$, Sikap simpatik petugas samsat dalam melayani $\left(\mathrm{X}_{14}\right)$, Tata ruang yang tidak membosankan $\left(\mathrm{X}_{15}\right)$, Perubahan administrasi perpajakan $\left(\mathrm{X}_{16}\right)$, Sistem pelayanan cepat $\left(\mathrm{X}_{17}\right)$, Suasana ruang pelayanan yang nyaman $\left(\mathrm{X}_{18}\right)$, Pengetahuan terhadap denda pajak $2 \%$ per bulan $\left(\mathrm{X}_{19}\right)$, Kesadaran wajib pajak $\left(\mathrm{X}_{20}\right)$.

\section{Prosedur Analisis}

Langkah-langkah menganalisis data dengan analisis faktor eksploratori, dijelaskan sebagai berikut:

1. Membentuk matriks korelasi antar variabel

2. Melakukan pengujian terhadap matriks korelasi antar variabel dengan tiga uji statistik yaitu Uji Kaiser Meyer Oikin (KMO), Uji Bartlett, dan Uji Measures of Sampling Adequacy (MSA).

3. Melakukan ekstraksi faktor dengan metode ekstrasi Analisis Komponen Utama (Principal Components Analysis).

4. Melakukan rotasi faktor dengan menggunakan rotasi Orthogonal dengan metode varimax.

5. Menginterpretasikan hasil penelitian.

\section{PEMBAHASAN}

\section{Uji Kaiser Meiyer Olkin (KMO) dan Uji Bartlett's}

Uji KMO dilakukan untuk mengetahui faktorfaktor dalam penelitian itu valid atau tidak. Nilai KMO harus di atas 0,5.

$\mathrm{H}_{0}$ : Jumlah data cukup untuk difaktorkan

$\mathrm{H}_{1}$ : Jumlah data tidak cukup untuk difaktorkan

Uji Bartlett's bertujuan untuk mengetahui apakah terdapat hubungan antar variabel. Nilai $p$ value harus di bawah 0,05 .

$\mathrm{H}_{0}$ : Matriks korelasi merupakan matriks Identitas ( $\mathrm{p}=\mathrm{I})$

$\mathrm{H}_{1}$ : Matriks korelasi bukan merupakan matriks Identitas $(\mathrm{p} \neq \mathrm{I})$

Tabel 1. Nilai KMO dan Uji Bartlett's 


\begin{tabular}{|c|c|c|c|}
\hline Chi-squared & Df & p-value & KMO \\
\hline 1217,084 & 153 & $<4,47 \mathrm{e}-165$ & 0,83 \\
\hline
\end{tabular}

Dari Tabel 1, di dapat nilai $\mathrm{KMO}=0,83$ dengan taraf signifikan 5\%. Karena 0,83>0,5 artinya Ho diterima, maka dapat disimpulkan bahwa jumlah data cukup untuk difaktorkan.

Kemudian untuk uji Bartlett's di dapat nilai $p$ value $=<4,47 \mathrm{e}-165$ atau 0,000 . Karena $0,000<$ 0,05 artinya $\mathrm{H}_{0}$ ditolak, maka dapat disimpulkan bahwa variabel tersebut dapat dianalisis lebih lanjut dengan menggunakan analisis faktor.

\section{Uji Measure of Sampling Adequacy (MSA)}

Measure of Sampling Adequacy (MSA) digunakan untuk melihat variabel mana saja yang layak dibuat analisis faktor, serta untuk mengetahui faktor analisis tersebut memiliki korelasi yang kuat atau tidak dengan nilai yang lebih besar atau sama dengan 0,05. Angka MSA (Measure of Sampling Adequacy) berkisar 0 sampai 1.

Tabel 2. Nilai Measure of Sampling Adequacy (MSA)

\begin{tabular}{|c|c|c|c|}
\hline Item & MSA & Item & MSA \\
\hline Pert1 & 0.90 & Pert12 & 0.88 \\
\hline Pert3 & 0.90 & Pert13 & 0.85 \\
\hline Pert5 & 0.71 & Pert14 & 0.88 \\
\hline Pert6 & 0.68 & Pert15 & 0.87 \\
\hline Pert7 & 0.68 & Pert16 & 0.77 \\
\hline Pert8 & 0.84 & Pert17 & 0.87 \\
\hline Pert9 & 0.78 & Pert18 & 0.80 \\
\hline Pert10 & 0.78 & Pert19 & 0.85 \\
\hline Pert11 & 0.89 & Pert20 & 0.74 \\
\hline
\end{tabular}

Berdasarkan Tabel 2, didapat nilai MSA untuk setiap variabel lebih besar dari 0,5 dengan taraf signifikan 5\%. Maka dapat disimpulkan bahwa keseluruhan variabel bisa diprediksi variabel lain dan dapat dianalisis lebih lanjut.

\section{Ekstraksi Faktor}

Nilai eigenvalue harus berada di atas satu (1) jika dibawah satu (1) maka tidak bisa dijadikan faktor terbentuk. Jumlah eigenvalue susunannya selalu diurutkan dari nilai yang terbesar sampai yang terkecil.

Tabel 3. Nilai Eigenvalue

\begin{tabular}{|c|c|c|c|}
\hline Component & Eigenvalue & Component & Eigenvalue \\
\hline 1 & $\mathbf{5 , 0 3 2}$ & 10 & 0,633 \\
\hline 2 & $\mathbf{2 , 4 6 2}$ & 11 & 0,577 \\
\hline 3 & $\mathbf{1 , 3 2 3}$ & 12 & 0,481 \\
\hline 4 & $\mathbf{1 , 1 4 7}$ & 13 & 0,455 \\
\hline 5 & $\mathbf{1 , 1 0 5}$ & 14 & 0,394 \\
\hline 6 & 0,868 & 15 & 0,364 \\
\hline 7 & 0,821 & 16 & 0,336 \\
\hline 8 & 0,734 & 17 & 0,299 \\
\hline 9 & 0,684 & 18 & 0,283 \\
\hline
\end{tabular}

Berdasarkan Tabel 3, dapat dilihat bahwa jumlah faktor yang terbentuk sebanyak 5 faktor. Hal ini dikarenakan kelima faktor tersebut telah memenuhi syarat dengan nilai eigenvalue-nya lebih dari 1, tetapi untuk ke-13 faktor nilai eigenvalue-nya kurang dari 1 , yaitu 0,868 dan yang terkecil dengan nilai 0,283. Sehingga proses factoring hanya terbentuk pada 5 faktor saja.

\section{Rotasi Faktor}

Rotasi dengan metode varimax terhadap faktorfaktor yang akan terbentuk dimaksudkan agar nilai loading factor yang dihasilkan tersebut konsisten dengan membuat korelasi variabel yang hanya dominan pada satu faktor atau yang korelasinya besar.

Tabel 4. Rotasi Faktor dengan Metode Varimax

\begin{tabular}{|l|c|c|c|c|c|}
\hline & MR1 & MR2 & MR5 & MR3 & MR4 \\
\hline Pert1 & $\mathbf{0 , 2 6}$ & 0,12 & 0,25 & 0,12 & $-0,03$ \\
\hline Pert3 & 0,21 & 0,21 & $\mathbf{0 , 3 8}$ & 0,16 & 0,05 \\
\hline Pert5 & $-0,04$ & $\mathbf{0 , 5 5}$ & $-0,07$ & 0,18 & $-0,06$ \\
\hline Pert6 & 0,25 & $-0,01$ & 0,10 & $-0,17$ & $\mathbf{0 , 6 8}$ \\
\hline Pert7 & 0,03 & 0,08 & 0,00 & 0,41 & $\mathbf{0 , 4 7}$ \\
\hline Pert8 & 0,29 & 0,01 & $\mathbf{0 , 7 3}$ & $-0,01$ & 0,08 \\
\hline Pert9 & 0,24 & 0,28 & 0,15 & $\mathbf{0 , 7 3}$ & 0,00 \\
\hline Pert10 & 0,17 & 0,20 & 0,15 & $\mathbf{0 , 6 4}$ & 0,00 \\
\hline Pert11 & $\mathbf{0 , 5 8}$ & 0,04 & 0,37 & 0,18 & 0,08 \\
\hline Pert12 & $\mathbf{0 , 6 8}$ & 0,11 & 0,17 & 0,02 & 0,23 \\
\hline Pert13 & $\mathbf{0 , 8 0}$ & 0,02 & 0,20 & 0,07 & 0,10 \\
\hline Pert14 & $\mathbf{0 , 7 3}$ & 0,09 & 0,18 & 0,06 & 0,08 \\
\hline Pert15 & 0,18 & $\mathbf{0 , 5 6}$ & 0,21 & 0,24 & 0,09 \\
\hline Pert16 & $-0,03$ & $\mathbf{0 , 3 9}$ & 0,30 & 0,21 & 0,18 \\
\hline Pert17 & $\mathbf{0 , 4 9}$ & 0,42 & 0,21 & $-0,09$ & $-0,04$ \\
\hline Pert18 & 0,22 & $\mathbf{0 , 8 0}$ & 0,07 & 0,15 & 0,01 \\
\hline Pert19 & 0,37 & 0,06 & $\mathbf{0 , 6 1}$ & $-0,15$ & 0,03 \\
\hline Pert20 & $-0,14$ & 0,13 & $-0,18$ & $\mathbf{0 , 4 1}$ & $-0,05$ \\
\hline
\end{tabular}

Berdasarkan hasil loading pada Tabel 4, penentuan faktor dari variabel adalah dengan melihat nilai matriks korelasi (nilai mutlak) terbesar antara tiap variabel dengan tiap faktor. Misalnya nilai terbesar untuk matriks korelasi variabel Pert13 adalah terdapat pada komponen 
MR1 (faktor pertama) dengan nilai korelasi sebesar 0,80 maka variabel Pert13 masuk di faktor pertama. Begitu pula dengan variabel Pert18, nilai matriks korelasi terbesar berada pada komponen MR2 (faktor kedua) dengan nilai korelasi sebesar 0,80 maka variabel Pert 18 masuk di faktor kedua.

\section{Interpretasi Hasil}

Hasil analisis faktor keseluruhan dapat dilihat pada Tabel 5 berikut:

Tabel 5. Hasil Interpretasi Variabel

\begin{tabular}{|c|c|c|c|c|c|c|}
\hline No. & Var & Faktor & $\begin{array}{l}\text { Eigen } \\
\text { values }\end{array}$ & $\begin{array}{l}\text { Loading } \\
\text { faktor }\end{array}$ & $\begin{array}{c}\text { Variansi } \\
(\%)\end{array}$ & $\begin{array}{c}\text { Komulatif } \\
(\%)\end{array}$ \\
\hline 1. & $\mathrm{X}_{1}$ & \multirow{6}{*}{$\begin{array}{l}\text { Kualitas } \\
\text { pelayanan }\end{array}$} & \multirow{6}{*}{5,032} & 0,26 & \multirow{6}{*}{27,96} & \multirow{6}{*}{27,96} \\
\hline 2. & $\mathrm{X}_{11}$ & & & 0,58 & & \\
\hline 3. & $\mathrm{X}_{12}$ & & & 0,68 & & \\
\hline 4. & $\mathrm{X}_{13}$ & & & 0,80 & & \\
\hline 5. & $\mathrm{X}_{14}$ & & & 0,73 & & \\
\hline 6. & $\mathrm{X}_{17}$ & & & 0,49 & & \\
\hline 7. & $\mathrm{X}_{5}$ & \multirow{4}{*}{$\begin{array}{c}\text { Tata ruang dan } \\
\text { administrasi } \\
\text { perpajakan }\end{array}$} & \multirow{4}{*}{2,462} & 0,55 & \multirow{4}{*}{13,68} & \multirow{4}{*}{41,64} \\
\hline 8. & $\mathrm{X}_{15}$ & & & 0,56 & & \\
\hline 9. & $\mathrm{X}_{16}$ & & & 0,39 & & \\
\hline 10. & $\mathrm{X}_{18}$ & & & 0,80 & & \\
\hline 11. & $\mathrm{X}_{9}$ & \multirow{3}{*}{$\begin{array}{l}\text { Sosialisasi } \\
\text { perpajakan }\end{array}$} & \multirow{3}{*}{1,323} & 0,73 & \multirow{3}{*}{7,35} & \multirow{3}{*}{48,99} \\
\hline 12. & $\mathrm{X}_{10}$ & & & 0,64 & & \\
\hline 13. & $\mathrm{X}_{20}$ & & & 0,41 & & \\
\hline 14. & $\mathrm{X}_{6}$ & \multirow{2}{*}{$\begin{array}{c}\text { Pengetahuan } \\
\text { dan pemahaman } \\
\text { perpajakan }\end{array}$} & \multirow{2}{*}{1,147} & 0,68 & \multirow{2}{*}{6,37} & \multirow{2}{*}{55,36} \\
\hline 15. & $\mathrm{X}_{7}$ & & & 0,47 & & \\
\hline 16. & $\mathrm{X}_{3}$ & \multirow{3}{*}{ Pendidikan } & \multirow{3}{*}{1,105} & 0,38 & \multirow{3}{*}{6,14} & \multirow{3}{*}{61,50} \\
\hline 17. & $\mathrm{X}_{8}$ & & & 0,73 & & \\
\hline 18. & $\mathrm{X}_{19}$ & & & 0,61 & & \\
\hline
\end{tabular}

Berdasarkan Tabel 5, maka model faktor yang terbentuk adalah :

$$
\begin{aligned}
\mathrm{F}_{1}= & 0,26 \mathrm{X}_{1}+0,58 \mathrm{X}_{11}+0,68 \mathrm{X}_{12}+0,80 \mathrm{X}_{13}+ \\
& 0,73 \mathrm{X}_{14}+0,49 \mathrm{X}_{17} \\
\mathrm{~F}_{2}= & 0,55 \mathrm{X}_{5}+0,56 \mathrm{X}_{15}+0,39 \mathrm{X}_{16}+0,80 \mathrm{X}_{18} \\
\mathrm{~F}_{3}= & 0,73 \mathrm{X}_{9}+0,64 \mathrm{X}_{10}+0,41 \mathrm{X}_{20} \\
\mathrm{~F}_{4}= & 0,68 \mathrm{X}_{6}+0,47 \mathrm{X}_{7} \\
\mathrm{~F}_{5}= & 0,38 \mathrm{X}_{3}+0,73 \mathrm{X}_{8}+0,61 \mathrm{X}_{19}
\end{aligned}
$$

\section{KESIMPULAN}

Berdasarkan hasil dan pembahasan yang diperoleh, dapat disimpulkan bahwa faktorfaktor yang mempengaruhi kepatuhan wajib pajak orang pribadi dalam memenuhi kewajiban membayar pajak PKB di kantor samsat Takalar, dari 18 variabel yang mempengaruhi menjadi 5 faktor yaitu:

1. Faktor pertama yakni kualitas pelayanan, dengan indikator : (a) Kemampuan petugas samsat menjelaskan tata cara pembayaran pajak dengan baik, (b) Sikap simpatik petugas samsat dalam melayani, (c) Sikap tanggap petugas samsat dalam menyelesaikan masalah, (d) Kemampuan petugas samsat dalam membantu dan menjawab pertanyaan tentang pajak, (e) Sistem pelayanan cepat, (f) Tarif pajak yang sesuai.

2. Faktor kedua yakni tata ruang dan administrasi perpajakan, dengan indikator : (a) Suasana ruang pelayanan yang nyaman, (b) Tata ruang yang tidak membosankan, (c) Penertiban pajak, (d) Perubahan administrasi perpajakan.

3. Faktor ketiga yakni sosialisasi perpajakan, dengan indikator : (a) Sosialisasi pembayaran pajak, (b) Sosialisasi pajak, (c) Kesadaran wajib pajak.

4. Faktor keempat yakni pengetahuan dan pemahaman perpajakan, dengan indikator : (a) Pajak sumber pemasukan dana terbesar, (b) Pajak sumber pendapatan.

5. Faktor kelima yakni pendidikan, dengan indikator : (a) Tingkat pendidikan, (b) Tingkat pendapatan, (c) Pengetahuan terhadap denda pajak $2 \%$ per bulan.

\section{DAFTAR PUSTAKA}

[1] Sauddin, Adnan. Eksploratory Factor Analysis Decision Process : Guide For Students and Researchs - Bagian 1. Jurnal MSA Vol.2 No.1 Edisi Januari - Juni 2014.

[2] Jhonson, Richard dan Wichern, "Applied Multivariate Statistical Analysis", (New Jersey : University of Wisconsin, Prentice Hall inc, 1982).

[3] Marcus, G. L, H. J. Wattimanela dan Y. A. Lesnussa. Analisis Regresi Komponen Utama Untuk Mengatasi Masalah Multikolinieritas Dalam Analisis Regresi Linear Berganda. Jurnal Barekeng Vol. 6 No. 1, 2012.

[4] Undang-Undang RI No.28 Tahun 2009 Tentang Pajak Daerah dan Retribusi Daerah.

[5] Ilhamsyah, Randi, Maria G Wi Endang dan Rizky Yudhi Dewantara. Pengaruh Pemahaman dan Pengetahuan Wajib Pajak Tentang Peraturan Perpajakan, Kesadaran Wajib Pajak, Kualitas Pelayanan, dan Sanksi Perpajakan 
Terhadap Kepatuhan Wajib Pajak Kendaraan Bermotor (Studi Samsat Kota Malang). Jurnal Perpajakan (JEJAK) Vol. 8 No. 1, 2016. 